\title{
Chronic Lymphocytic Leukaemia: Up-Dated Recommendations on Diagnosis and Treatment
}

\author{
$\begin{array}{lll}\text { M. Hallek } & \text { M. Bergmann } & \text { B. Emmerich } \\ & \text { B for the German CLL Study Group* }\end{array}$ \\ ${ }^{a}$ Klinik I für Innere Medizin, Universität Köln, \\ b Medizinische Klinik III, Klinikum der Universität München, Großhadern, \\ ${ }^{\mathrm{c}}$ Medizinische Klinik, Klinikum der Universität München, Innenstadt, Germany
}

\section{Key Words}

Chronic lymphatic leukaemia, treatment, diagnosis .

CLL · Fludarabine - Monoclonal antibodies .

Clinical trials

\section{Summary}

Diagnosis and treatment of chronic lymphatic leukaemia (CLL) are currently undergoing great change. New knowledge of prognosis factors and the numerous new therapeutic procedures now available, such as purine analogues, high-dose treatment and monoclonal antibodies are making major contributions to this progress. As a consequence, the options for treatment of CLL are considerably more diverse now than a few years ago, and now include procedures that take into account age and risk. At the same time, it should be emphasized that many important questions regarding the treatment of CLL remain unresolved. It is anticipated that these questions will be answered over the coming few years by including patients in multicentre studies like those being carried out by the German CLL study group.

\footnotetext{
*The Consensus presented in this publication was obtained after discussion within the German CLL Study Group involving the following colleagues: L. Bergmann (Frankfurt), L. Böning (Munich), G. Brittinger (Essen), P. Daniel (Berlin), V. Diehl (Cologne), H. Döhner (Ulm), B. Dörken (Berlin), P. Dreger (Hamburg), G. Ehninger (Dresden), A. Engert (Cologne), A. Franke (Magdeburg), H. Heimpel (Ulm), K.P. Hellriegel (Berlin), M. Herold (Erfurt), W. Hiddemann (Munich), G. Hopfinger (Vienna), D. Huhn (Berlin), U. Jäger (Vienna), W. Kern (Munich), W. Knauf (Berlin), M. Kneba (Kiel), H.-J. Kolb (Munich), W.D. Ludwig (Berlin), K. Lechner (Vienna), O. Meyer (Berlin), A. Neubauer (Marburg), C. Nerl (Munich), C. Peschel (Munich), H. Pralle (Giessen), M. Rummel (Frankfurt), B. Schmitt (Munich), N. Schmitz (Hamburg), S Serke (Berlin), W. Siegert (Berlin), H. Stein (Berlin), S. Stilgenbauer (Ulm), T. Südhoff (Passau), E. Thiel (Berlin), M. Wilhelm (Nürnberg), N. Willich (Münster).
}

\begin{tabular}{ll}
\hline KARGER & @ 2004 S. Karger GmbH, Freiburg \\
Fax +497614520714 & Accessible online at: \\
$\begin{array}{l}\text { E-mail Information@Karger.de } \\
\text { www.karger.com }\end{array}$ & www.karger.com/onk \\
&
\end{tabular}

\author{
Schlüsselwörter \\ Chronische lymphatische Leukämie, Behandlung, \\ Diagnose · CLL · Fludarabin · Monoklonale Antikörper . \\ Klinische Studien
}

\section{Zusammenfassung}

Die Diagnostik und Behandlung der chronischen lymphatischen Leukämie (CLL) ist derzeit starken Änderungen unterworfen. Neue Erkenntnisse zu Prognosefaktoren und neue Therapieverfahren wie Purinanaloga, Hochdosistherapie und monoklonale Antikörper trugen wesentlich zu diesem Fortschritt bei. Die Behandlung der CLL ist heute wesentlich differenzierter zu sehen als noch vor wenigen Jahren und erfordert eine alters- und risikoangepasste Vorgehensweise. Es ist gleichzeitig zu betonen, dass noch viele wesentliche Fragen zur Therapie der CLL offen sind. Nur durch Behandlung der Patienten im Rahmen von multizentrischen Studien, wie sie die Deutsche CLL-Studiengruppe im deutschsprachigen Raum durchführt, werden diese Fragen in den nächsten Jahren zu beantworten sein.

\section{Epidemiology}

Chronic lymphatic leukaemia (CLL) is a leukaemic nonHodgkin's lymphoma of the B-cell type. With an annual incidence of 3 cases per 100,000, it is the most common leukaemia of adulthood in the Western Hemisphere. The median age of onset is 65-70 years, and while the risk of developing CLL increases with age, no age plateau is reached. About $20 \%$ of patients are younger than 55 years at diagnosis and the proportion of these younger patients has been increasing in recent years. This is due to earlier diagnosis because of blood counts 
Table 1. Binet staging system and prognosis of CLL [6]

\begin{tabular}{|c|c|c|}
\hline Stage & Definition & $\begin{array}{l}\text { Median } \\
\text { survival at } \\
\text { diagnosis, } \\
\text { years }\end{array}$ \\
\hline A & $\begin{array}{l}\text { Peripheral blood lymphocytosis }>5000 / \mu \mathrm{l}, \\
\mathrm{Hb} \geq 10 \mathrm{~g} / \mathrm{dl} \text {, thrombocytes } \geq 100,000 / \mu \mathrm{l}, \text { up to } \\
2 \text { lymph node regions* involved }\end{array}$ & $>10$ \\
\hline B & At least 3 lymph node regions* involved & 5 \\
\hline $\mathrm{C}$ & $\mathrm{Hb}<10 \mathrm{~g} / \mathrm{dl}$ or thrombocytes $<100,000 / \mu \mathrm{l}$ & $2-3$ \\
\hline \multicolumn{3}{|c|}{$\begin{array}{l}\text { *Lymph node regions: axillary, inguinal, cervical lymph nodes, as well } \\
\text { as spleen and liver (maximum } 5 \text { regions); palpation is the basis for } \\
\text { classification. }\end{array}$} \\
\hline
\end{tabular}

performed for other reasons. Appropriate advice and care for these younger CLL patients will be of greater significance in future [1].

The aetiology of CLL is unclear. The possible influence of environmental factors is under debate, and not yet established. Genetic factors play a part: children of CLL patients are at higher risk of contracting CLL or another lymphatic neoplasia than the normal population [2].

\section{Clinical Symptoms, Disease Progression and Grading of Stages}

As with other lymphomas, there is no reliable key symptom of CLL. It is usually asymptomatic in the early stages, the most common symptom being the occurrence of enlarged lymph nodes. At an advanced stage, other symptoms, such as reduced physical and mental stamina, B symptoms and infections, also occur frequently.

The mean survival period from the time of diagnosis varies between 2 and more than 10 years, depending on the stage. The stage classifications of Binet et al. [3] and Rai et al. [4] are used to estimate the prognosis. Both are based on the extent of lymphadenopathy, splenomegaly and hepatomegaly measured by palpation, and anaemia and thrombocytopenia measured by blood tests. The Binet staging system is simpler and more widely used throughout Europe. It separates three major prognostic subgroups (table 1) [5, 6].

However, the Binet staging system alone is not sufficient to reliably estimate the individual prognosis in the early stages, especially in younger patients (Binet stage A, Rai stages 0-II). The following parameters indicate an unfavourable prognosis, irrespective of the stage $[5,6]$ :

- a lymphocyte doubling time of less than 12 months,

- increased serum lactate dehydrogenase (LDH) activity,

- elevated serum $\beta_{2}$-microglobulin concentration,

- elevated serum thymidine kinase activity,

- increased serum levels of soluble CD23,
Table 2. Typical surface antigen profile of B-CLL

\begin{tabular}{ll}
\hline Cell surface antigen & Intensity of expression \\
\hline Membrane-resistant immunoglobulins & weak \\
CD5 & positive \\
CD23 & positive \\
FMC7 & negative \\
CD79 $\beta$ & negative \\
\hline
\end{tabular}

- aberrations in chromosomes 11 (11q-) and 17 (17p-),

- lack of somatic hyper-mutations of the immunoglobulin $\mathrm{V}_{\mathrm{H}^{-}}$ gene region,

- CD38 positivity of the CLL cells,

- a diffuse or non-nodular bone marrow infiltration.

The relative weighting of these prognosis factors is currently being determined in studies. A recent interim analysis of the CLL1 protocol of the German CLL study group suggests that cytogenetics (11q-, 17p-, trisomy 12), serum thymidine kinase, and lymphocyte doubling time are more potent than the other parameters in predicting progression-free survival of earlystage CLL patients.

\section{Diagnostic and Prognostic Factors}

Two examinations are required to diagnose CLL: (1) The evaluation of blood count and blood smear and (2) the immune phenotyping of the leukaemia cells in the peripheral blood (see A and B, below) [7]. In addition, histopathological evaluation of an enlarged lymph node is important in cases of doubtful diagnosis (see $\mathrm{C}$, below). Further examinations enable early recognition of complications, assessment of the prognosis or the establishment of the extent of the leukaemia (D-G, below).

A. Blood count and blood smear: Permanent elevation of the absolute lymphocyte count to a value higher than $5 \mathrm{~g} / 1$ is typical and is a requirement for the diagnosis of CLL. Typical BCLL cells are found in the blood smear - i.e. small lymphocytes with a narrow border of cytoplasm and a dense nucleus with partially aggregated chromatin, and without recognizable nucleoli. Gumprecht nuclear shadows, found as cell debris, are characteristic.

B. Immune phenotyping: The immune phenotyping examination of the lymphocytes from peripheral blood is required for the diagnosis of CLL. The malignant cells can be classified as $\mathrm{B}$ - or T-cell forms. The evidence of light chain restriction ( $\kappa$ or $\lambda$ type) is an important indication of the monoclonal nature of the cells [8]. The typical antigen sample of CLL cells in flow cytometry is similar to that of lymphocytes in the region of the mantle zone of secondary lymphatic follicles. Co-expression of the antigen $\mathrm{CD} 5$, with a weak expression of membrane-resistant immunoglobulins (IgM with or without $\operatorname{IgD}$ ) and the expression of B-cell associated membrane antigens, such as 
Table 3. The most common chromosome aberrations in CLL

\begin{tabular}{ll}
\hline Chromosome aberration & Frequency, \% \\
\hline 13q deletion & 55 \\
11q deletion & 18 \\
Trisomy 12 & 16 \\
17p deletion & 7 \\
6q deletion & 6 \\
Trisomy 8 & 5 \\
Trisomy 3 & 3 \\
\hline
\end{tabular}

CD19 and CD23, is characteristic. CD20 is expressed only weakly, and FMC7 and CD79 $\beta$ are generally not expressed. The typical surface antigen profile of CLL is summarized in table $2[9,10]$.

C. Histopathology of an enlarged lymph node: Lymph-node histology permits the evaluation of the lymph-node architecture, which varies in non-Hodgkin's lymphomas. This enables a better distinction of CLL from related entities that express similar surface markers. It can be particularly difficult to differentiate between lympho-plasmocytic lymphoma (immunocytoma), mantle-cell lymphoma and marginal zone lymphoma. Histological diagnosis provides additional confirmation of this, and enables the disease to be categorized according to the REAL or WHO classifications [11]. An impoverished lymph node architecture, with the loss of nuclear cores and obliteration of the sinus by infiltrates of small lymphatic cells, is characteristic of the histological appearance of CLL. The predominant cells are small lymphocytes with aggregated chromatin, a (mainly) round nucleus and occasionally a small nucleolus. Larger lymphatic cells are regularly seen (pro-lymphocytes and paraimmunoblasts), and are usually arranged in foci termed pseudo-follicles or proliferation centres.

D. Measurement of other laboratory parameters: Serum LDH, serum electrophoresis to detect paraproteinaemia and serum immunoglobulins to determine secondary antibody deficiency should be measured. The Coombs test serves to detect antierythrocyte auto-antibodies. The lymphocyte doubling time (with observations over at least 3 months) is calculated from the blood count values. Serum measurements of creatinine, urea, electrolytes, uric acid, bilirubin and transaminases, as well as of urine status are also performed before treatment is started. Serum thymidine kinase and serum $\beta_{2}$-microglobulin are measured to assess the prognosis.

E. Imaging procedures: Following the physical examination of the patient, and determination of the lymph-node status, an ultrasound scan of the abdomen is performed and an X-ray of the thorax taken, in order to assess the involvement of abdominal or intra-thoracic organs and the extent of the lymphnode enlargements in these regions. With doubtful lymphomas, or those causing complications, computer tomography of the thorax or the abdomen might also be indicated.

F. Bone marrow examination: Cytological and histological ex- amination of bone marrow is not necessary for diagnosis [8]. Histological examination of bone marrow allows the extent and pattern of bone marrow infiltration by CLL (diffuse, nodular) to be measured. These parameters have prognostic significance. If unclear cytopenia occurs in the course of the disease, bone-marrow puncture may explain the aetiology (leukaemia infiltration, increased megacaryopoesis in autoimmune cytopenia, bone-marrow aplasia after chemotherapy). Bone-marrow puncture with cytological and histological examination is indicated if there is complete regression of all disease indications following the treatment: complete remission (CR) of CLL can be determined only after the bone-marrow findings are known (see below for criteria used to evaluate treatment-related progress).

G. Cytogenetics: In more than $80 \%$ of CLL patients, confirmation of chromosomal aberrations is obtained by interphase cytogenetics (fluorescence in-situ hybridization, FISH). The biological significance of such abnormalities is unclear. Certain aberrations have prognostic value [12]. Deletion of chromosome $13 \mathrm{q}$ is the most common and indicates a favourable prognosis (table 3 ).

Patients with $17 \mathrm{p}$ or $11 \mathrm{q}$ deletion have a poorer prognosis than patients with a normal karyotype or with $13 \mathrm{q}$ deletion. $17 p$ and $11 q$ deletions occur almost exclusively in CLL clones with unmutated genes for the heavy chain of the immunoglobulin $(\operatorname{IgH})$. Patients with the $11 \mathrm{q}$ deletion are also clinically different; they often show marked lymphatic adenopathy and B symptoms. The implications of these findings for therapeutic decision-making requires clarification in prospective studies $[8,13]$.

\section{Therapeutic Indications and Options}

The decision to treat is guided by the stage of the disease, the presence of symptoms and the disease activity. Only patients in Rai III and IV or Binet C stages should be treated. Patients in earlier stages should be treated only if symptoms associated with the disease occur. Symptoms associated with the disease that justify a decision to treat are: severe B symptoms, a severe loss of performance, and symptoms or threatening complications from spleen or liver enlargement and lymphomas (e.g. compression of the large abdominal vessels). High disease activity, which is defined by a lymphocyte doubling time of less than 6 months or by rapidly growing lymphomas, is also an indication to treat in the early stages. Autoimmune haemolytic anaemia or secondary immune thrombocytopenia with a risk of haemorrhage are treated with corticosteroids; these signs, as such, are no indication for cytostatic chemotherapy. Treatment should not be administered in the early stages of the disease (Rai stages 0-II, Binet stages A and B) without symptoms of the disease and without disease activity. These patients should be only monitored on a regular basis ('watch-and-wait' approach). 
Previously, CLL was treated for palliative reasons, as it was not possible to achieve lasting complete remissions with conventional therapeutic measures. The development of new therapeutic options has changed this. Younger patients are now treated more intensively, with the aim of achieving the longest possible complete remission, thereby prolonging (disease-free) survival.

\section{Current and Future Investigations of the German CLL Study Group}

The German CLL study group (GCLLSG) has set itself the goal of permanently improving the treatment of CLL. Foremost among these concerns are the improvement of quality of life and the lengthening of the period in which patients are free of symptoms and disease, and prolongation of life itself. For this reason, the GCLLSG has developed treatment plans for all major age and risk groups. In the CLL1 protocol for patients in Binet stage $\mathrm{A}$, the risk of progression is first determined. Patients with a high risk of progression (non-nodular bone-marrow infiltration or lymphocyte doubling time of $<12$ months and elevation of serum thymidine kinase or of serum $\beta_{2}$-microglobulin) are either observed or treated with fludarabine after randomization. Patients with a low risk of progression are observed. The CLL1 protocol will be replaced in 2004 by the CLL7 protocol investigating the benefit of a triple combination chemo-immunotherapy with fludarabine, cyclophosphamide and rituximab (FCR) in patients at high risk (as defined by molecular cytogenetics, elevated serum thymidine kinase, short lymphocyte doubling time, and unmutated immunoglobulin status) versus a watch-and-wait strategy.

When a clear indication to treat is presented (Binet stage $\mathrm{C}$ or stage B with symptoms), treatment will be initiated, its intensity depending on patient's age or physical fitness. The CLL4 protocol was designed for patients aged up to 65 years and compared fludarabine $(\mathrm{F})$ with the combination of fludarabine and cyclophosphamide (FC). The trial was closed in July 2003. Preliminary results show that FC is causing more myelosuppression but induces twice as many complete remissions as $\mathrm{F}$ alone. The CLL4 protocol was replaced in August 2003 by the CLL8 protocol, which compares FC versus FC plus rituximab in primary treatment of younger and physically robust patients with CLL.

The CLL5 protocol, for patients aged 66 years and above, compares chlorambucil with fludarabine. It will be replaced in 2004 by the CLL9 protocol testing the benefit of erythropoietin as a supportive treatment in elderly patients treated by a mild chemotherapy (fludarabine).

In a relapse situation, patients are treated in the context of the CLL6 protocol, in which the combination of fludarabine, cyclophosphamide and mitoxantrone (FCM), which also achieves a response in patients resistant to fludarabine, is used for all patients. This protocol tests whether the administration of granulocyte-stimulating factor (G-CSF) prevents the occurrence of severe infections.

The protocols are constantly being extended by innovative procedures. New substances or combinations are tested in phase II protocols (CLL2H and CLL2I with alemtuzumab; CLL2G with CHOP (cyclophosphamide, doxorubicin, vincristine and prednisone) plus rituximab). Experimental treatment procedures, such as high-dose chemotherapy with autologous stem-cell replacement (CLL3C protocol) or allogeneic stem-cell transplantation (CLL3X protocol), are also being tested by the GCLLSG.

\section{Key Elements of Anti-Leukaemia Treatment}

\section{A. Conventional Chemotherapy}

Chlorambucil: The standard treatment for CLL patients in advanced stages was previously oral monotherapy with chlorambucil [14]. Chlorambucil is an alkylating drug that is usually well tolerated. Remission rates of up to $40 \%$ can be achieved with chlorambucil, but complete remissions are achieved only rarely, and partial remissions are of short duration. There is no advantage in combining chlorambucil with corticosteroids, except in autoimmune complications.

There are two, largely equivalent, methods of administration: (1) $0.4-0.8 \mathrm{mg} / \mathrm{kg}$ body weight on day 1 . A dose of $0.4 \mathrm{mg} / \mathrm{kg}$ body weight is administered initially. This dose is increased from one course to the next by $0.1 \mathrm{mg} / \mathrm{kg}$, depending on the response and the undesirable effects that occur. If there is an insufficient therapeutic response, the target dose of $0.8 \mathrm{mg} / \mathrm{kg}$ body weight may be exceeded, taking toxicity into account. The cycles of treatment are repeated at intervals of 14 days. (2) $0.07-0.1 \mathrm{mg} / \mathrm{kg}$ body weight per day, for a period of 14 days. The treatment cycle can be repeated after a pause of 14 days.

Following successful treatment with chlorambucil, it may be administered again after 12 months if there is renewed progression. If the disease progresses on chlorambucil treatment, or the effect of the treatment lasts for less than 12 months, other drug treatments should be selected.

Purine analogues: The treatment of CLL has changed greatly with the introduction of the purine analogues fludarabine and 2-chlordesoxyadenosine (cladribine). Purine analogues are the first substances that achieve a relatively high rate of complete remission, even as monotherapy drugs [15]. Fludarabine has been studied more thoroughly than cladribine. Fludarabine is administered intravenously at a dose of $25 \mathrm{mg} / \mathrm{m}^{2}$ on days $1-5$, at intervals of 4 weeks. Up to 6 cycles are carried out.

In primary treatment, the use of fludarabine results in response rates of approximately $80 \%$, and around one third of all patients achieve complete remission $[16,17]$. In patients previously treated with alkylating drugs, the response rates are between 12 and $55 \%$, and in patients who are resistant to 
Table 4. Response rates of fludarabine and cyclophosphamide combinations

\begin{tabular}{|c|c|c|c|c|c|}
\hline Author, year [Reference] & Combination & Patients, $\mathrm{n}$ & $\mathrm{CR}, \%$ & $\mathrm{PR}, \%$ & OR, \% \\
\hline O'Brien et al., 2001 [45] & F $30 \mathrm{mg} / \mathrm{m}^{2}$ and CY $500 / 350 / 300 \mathrm{mg} / \mathrm{m}^{2} \mathrm{~d} 1-3$ & 93 CLL & 16 & 72 & 88 \\
\hline Hallek et al., 2001 [44] & $\mathrm{F} 25 \mathrm{mg} / \mathrm{m}^{2}$ and $\mathrm{CY} 250 \mathrm{mg} / \mathrm{m}^{2} \mathrm{~d} 1-3$ & 36 CLL & 16 & 75 & 91 \\
\hline \multirow[t]{2}{*}{ Frewin et al., 1999 [46] } & $\mathrm{F} 25 \mathrm{mg} / \mathrm{m}^{2}$ and $\mathrm{CY} 250 \mathrm{mg} / \mathrm{m}^{2} \mathrm{~d} 1-3$ & $10 \mathrm{NHL}$ & 0 & 50 & 50 \\
\hline & & 7 CLL & 28 & 43 & 71 \\
\hline \multirow[t]{2}{*}{ Flinn et al., 2000 [47] } & F $20 \mathrm{mg} / \mathrm{m}^{2} \mathrm{~d} 1-5$ and CY $600 \mathrm{mg} / \mathrm{m}^{2} \mathrm{~d} 1$, & $43 \mathrm{NHL}$ & 60 & 32 & 92 \\
\hline & G-CSF 5 mg/kg d8+ & 17 CLL & 47 & 53 & 90 \\
\hline Bosch et al., 2001 [49] & $\begin{array}{l}\mathrm{F} 25 \mathrm{mg} / \mathrm{m}^{2} \mathrm{~d} 1-3 \text { and CY } 300 \mathrm{mg} / \mathrm{m}^{2} \mathrm{~d} 1-3, \\
\text { mitoxantrone } 6 \mathrm{mg} / \mathrm{m}^{2} \mathrm{~d} 1\end{array}$ & 60 & $\begin{array}{l}50,18 \\
\text { molecular } \\
\text { CR }\end{array}$ & 28 & 78 \\
\hline
\end{tabular}

$\mathrm{CR}=$ Complete remission, $\mathrm{PR}=$ partial remission, $\mathrm{OR}=$ overall response rate, $\mathrm{F}=$ fludarabine, $\mathrm{CY}=$ cyclophosphamide, $\mathrm{G}-\mathrm{CSF}=$ granulocyte colony stimulating factor. alkylating drugs, between 20 and 40\% [18-20]. In the single phase III study that has been carried out to date, which compared fludarabine directly with chlorambucil in previously untreated patients, fludarabine achieved higher response rates (70 vs. $43 \%$ ), more complete remissions ( 27 vs. $3 \%$ ) and a longer period of survival free of progression (33 vs. 17 months), but with no clear extension of overall survival [21]. In comparison with more intensive multiple chemotherapy regimens, such as cyclophosphamide, doxorubicin and prednisone (CAP) or cyclophosphamide, doxorubicin, vincristine and prednisone (CHOP), fludarabine is at least as effective with regard to response rates and survival free of progression [22]. In relapses after previous treatment with fludarabine, a second chemotherapy with fludarabine results in further, high response rates between 67 and $83 \%$ [23].

The main adverse events of purine analogues are myelosuppression and lymphocytopenia, with low counts of CD4+-positive T lymphocytes, although this does not lead to a higher infection rate, in comparison to similar myelosuppressive treatments, such as CAP. However, the spectrum of germs observed is different from that occurring after myelosuppressive treatment with alkylating agents [24]. In about $1-5 \%$ of cases, autoimmune cytopenia occurs during treatment [25]. A tumour lysis syndrome rarely occurs during treatment with fludarabine [26]. The efficacy of cladribine is similar to that of fludarabine [27-29].

Monoclonal antibodies: Monoclonal antibodies bind to defined surface antigens and kill leukaemia cells by various mechanisms (apoptosis, complement activation, antibody-mediated cellular cytotoxicity). The use of monoclonal antibodies provides an opportunity for treatment of CLL and maintenance of remission. Monoclonal antibodies against CD20 (rituximab) [30] or against CD52 (alemtuzumab, formerly called Campath-1H) [31] are currently under examination for their efficacy in clinical studies. Most experience with monoclonal antibodies is in the treatment of relapses of CLL. In studies to date, rituximab alone led to partial remissions of short duration in $20-41 \%$ of patients $[32,33]$. When dose-intensified rituximab regimens are applied, the response rates may increase up to $75 \%[34,35]$. In patients with high leukaemia cell counts in the peripheral blood, there is a danger of severe undesired effects, caused not only by the release of cytokines from the leukaemia cells, but also by the agglutination of leukaemic cells in small blood vessels [36, 37].

Alemtuzumab is directed at CD52, which is expressed by normal B and T lymphocytes and almost all CLL cells. Undesirable effects of alemtuzumab are myelosuppression and T-cell depletion, which can lead to infectious complications [38]. Alemtuzumab shows its effect particularly in the peripheral blood and bone marrow. To date, alemtuzumab has been used primarily in relapses, and results in a response in about $42 \%$ of cases, with a relapse-free interval of $>12$ months [39]. Therefore, the substance was approved in 2001 for the treatment of relapses after fludarabine failure for CLL. A response rate of $89 \%$ was achieved in primary treatment [40]. The use of alemtuzumab as a post-remission consolidation therapy has been studied by the GCLLSG in the CLL4B protocol and by an Italian pilot study to test the hypothesis that leukaemia cells can be permanently eliminated in this way [41]. The main result of this trials is that a post-remission consolidation therapy with alemtuzumab can induce complete molecular remissions as demonstrated by real-time quantitative PCR (Wendtner, personal communication). However, the optimal timing and dosing schedule for alemtuzumab as consolidation therapy remains to be determined, as patients with low tumour load seem to require lower doses of alemtuzumab to achieve optimal effects at low toxicity.

Purine analogue combinations: In order to further improve treatment with purine analogues, combinations of fludarabine with cyclophosphamide and/or mitoxantrone were studied, because they act synergistically in vitro [42]. Amongst those, the combination of fludarabine and cyclophosphamide is by far the best studied (table 4). It achieves response rates of more than $80 \%$ in pretreated patients [43-47]. The combination of fludarabine and epirubicin in a study on previously treated patients also achieved response rates of over $80 \%$; among these patients, complete remission was achieved in about 30\% [48]. The triple combination of fludarabine, cyclophosphamide and 
Table 5. Response rates of combination therapies consisting of fludarabine or fludarabine/cyclophosphamide with rituximab

\begin{tabular}{|c|c|c|c|c|c|c|}
\hline Author, year [Reference] & Therapy & Patients, $\mathrm{n}$ & $\mathrm{CR}, \%$ & $\mathrm{nPR}, \%$ & $\mathrm{PR}, \%$ & OR, \% \\
\hline \multirow[t]{3}{*}{ Manero et al., 2001 [52] } & $\mathrm{FC}+\mathrm{R}$ alkylator-resistant & 15 & 20 & 13 & 33 & 80 \\
\hline & $\mathrm{FC}+\mathrm{R}$ F-sensitive & 60 & 30 & 15 & 33 & \\
\hline & $\mathrm{FC}+\mathrm{R}$ F-resistant & 27 & 7 & 11 & 41 & \\
\hline \multirow[t]{2}{*}{ Byrd et al., 2001 [51] } & $\mathrm{FC}+\mathrm{R}$ & 51 & 47 & & 43 & 90 \\
\hline & FC followed by $\mathrm{R}$ & 53 & 28 & & 49 & 77 \\
\hline Wierda et al., 2001 [50] & $\mathrm{FC}+\mathrm{R}$ primary therapy & 79 & 66 & 14 & 15 & 95 \\
\hline Schulz et al., 2002 [53] & $\mathrm{F}+\mathrm{R}$ & 29 & 34 & & 52 & 90 \\
\hline
\end{tabular}

$\mathrm{CR}=$ Complete remission, $\mathrm{nPR}=$ nodular partial remission, $\mathrm{PR}=$ partial remission, $\mathrm{OR}=$ overall response rate, $\mathrm{FC}=$ fludarabine and cyclophosphamide, $\mathrm{R}=$ rituximab. mitoxantrone induced $50 \%$ complete remissions in a study of relapsed patients [49]. The most common side effects of these fludarabine combinations are severe infections.

Moreover, the combination of fludarabine with monoclonal antibodies has yielded very promising results (table 5). The results obtained so far suggest that there is a synergistic antileukaemic effect of fludarabine and rituximab. The overall response rates are between 77 and $95 \%$. Most importantly, the rate of complete remissions obtained with this combination is between 20 and $66 \%$ except in fludarabine resistant patients $(7 \%)$. In particular the combination of fludarabine, cyclophosphamide and rituximab induces a high rate of complete remissions of $66 \%$ in untreated patients, a result so far unknown in the primary treatment of CLL [50]. In another study, 104 patients received fludarabine plus rituximab either simultaneously ( $\mathrm{n}=51$; on day 1 of each course) or sequentially ( $\mathrm{n}=53$; 6 courses of fludarabine followed by rituximab for 4 weeks) [51]. The response was significantly higher if rituximab was given simultaneously with fludarabine. The overall response rate was 90 versus $77 \%$, with 47 versus $28 \%$ complete remissions (table 5). These results suggest a synergistic mode of action of both drugs. Again, the major side effect of this combination therapy were severe, partially opportunistic infections. A combination of alemtuzumab and fludarabine was tested by Kennedy et al. [54] in 6 patients who were refractory to fludarabine. 5 of those responded to this therapy and 1 had a complete molecular remission. One patient had a pneumonia caused by Pseudomonas. There was no CMV (cyto megalo virus) reactivation. Taken together, these results suggest that the combination of fludarabine with monoclonal antibodies like rituximab and alemtuzumab is highly promising with regard to its potential to achieve complete molecular remissions. Further new drugs: The development of new compounds for the treatment of CLL is continuing. Currently, there are at least 20 new compounds in clinical testing $[55,56]$, most in phase I or II. These compounds include new chemical agents (e.g. bryostatin, bendamustin, flavopiridol, depsipeptide, phosphodiesterase inhibitors), monoclonal antibodies (e.g. antibodies against CD22, HLA-DR, or radio-conjugated antibodies), as well as genetic therapeutics (e.g. bcl2-antisense oligonucleotide Genasense ${ }^{\circledR}$ (Genta, Berkeley Heights, NJ, USA), gene therapy with adenovirus/CD154 vectors). A detailed review of these new agents is beyond the scope of this manuscript and given elsewhere $[55,56]$.

\section{B: High-Dose Therapy}

High-dose treatment with autologous stem-cell transplantation (SCT): Myeloablative high-dose (chemo)therapy, with subsequent autologous SCT, is an interesting experimental treatment for CLL which should be restricted to the framework of studies [57-59]. Until recently, the often indolent course of the disease and the high median age of patients contraindicated such intensive treatment. Because of the relative increase in the proportion of younger patients (aged $<55$ years) at high risk of disease progression, and because of the improvement in supportive measures, high-dose treatment with autologous SCT has grown in importance. The GCLLSG has studied this method of treatment in the CLL3 protocol in which, to date, more than 300 patients have been included. Mortality due to treatment is currently $5-10 \%$ in the large international studies and in the CLL3 protocol of the GCLLSG [58]. Because of the lack of randomised studies, it has not been possible to evaluate whether this therapeutic approach results in a better long-term prognosis than conventional chemotherapy. Therefore, the GCLLSG is now participating in a European randomised phase III trial (CLL3R protocol), which investigates the early versus delayed use of an autologous SCT after mobilisation following DexaBEAM polychemotherapy.

High-dose chemotherapy with allogeneic SCT: Because of the high mortality (between 25 and 50\%) [59] associated with treatment with allogeneic SCT in CLL, the administration of allogeneic SCT can be recommended only when used in the framework of studies. Reasons for the high mortality associated with treatment with allogeneic SCT include the immune defect associated with CLL, as well as the unfavourable patient selection (numerous previous treatments). Non-myeloablative conditioning protocols could improve the results [60]. Allogeneic SCT favours the graft-versus-leukaemia effect, which also plays a part in CLL, as is shown by the successful use of donor lymphocyte transfusions [61, 62]. 


\section{D: Radiation Treatment}

In curative treatment plans, radiation treatment is used as whole-body irradiation in the context of myeloablative radiochemotherapy with stem-cell transplantation (see above). As there are no definitive results from these studies, the use of radiation treatment in this context must be regarded as experimental. Irradiation with a palliative intention may be indicated in large lymphomas or leukaemia infiltrates, the elimination of which is of clinical importance. Radiation doses of between 10 and $40 \mathrm{~Gy}$ are used in normal fractionation. An adequate therapeutic effect is commonly reached at doses of only 20 Gy. Enlarged spleens causing severe discomfort due to space encroachment or cases of hypersplenism can be successfully treated by radiation therapy. This irradiation should be carried out in small individual doses (0.3-0.5 Gy, $3 \times$ weekly) as a very rapid fall in thrombocyte and leucocyte counts may occur otherwise. The total doses are between 3 and $10 \mathrm{~Gy}$.

\section{Supportive Treatment and Treatment of Complications}

Infections and autoimmune cytopenias are major complications of CLL. A detailed description of their management is beyond the scope of this review, but up-dated reviews on that issue have been published recently $[7,63]$.

\section{Summary: Consensus Recommendations}

During the past decade, much new information on pathogenesis, diagnosis and treatment of CLL has emerged. Treatment options in particular have increased considerably, through the availability of monoclonal antibodies and the increasing experience of high-dose treatment, in addition to other developments. Definitive treatment recommendations cannot therefore be given for many circumstances at this time. For example, it is at present unclear whether primary chemotherapy of B-CLL should be with chlorambucil, fludarabine or fludarabine combinations. The principal concern must therefore be to treat all patients in clinical studies.

The GCLLSG has developed a concept for an age- and riskadapted treatment of CLL in the framework of clinical studies. The long-term aim of these efforts is the continuous optimisation of treatment in order to achieve higher response rates, longer periods free of disease, a better quality of life and, perhaps in the future, a cure for the disease. However, without documented treatment of patients in clinical studies aiming at optimisation of therapy no relevant advance in knowledge will be achieved.

\section{References}

1 Mauro FR, Foa R, Giannarelli D, Cordone I, Crescenzi S, Pescarmona E, Sala R, Cerretti R, Mandelli F: Clinical characteristics and outcome of young chronic lymphocytic leukemia patients: A single institution study of 204 cases. Blood 1999:94:448-454.

2 Yuille MR, Matutes E, Marossy A, Hilditch B, Catovsky D, Houlston RS: Familial chronic lymphatic leukemia: A survey and review of published studies. Br J Haematol 2000;109:794-799.

3 Binet JL, Auquier A, Dighiero G, Chastang C, Piguet $\mathrm{H}$, Goasguen J, Vaugier G, Potron G, Colona P, Oberling F, Thomas M, Tchernia G, Jacquillat C, Boivin P, Lesty C, Duault MT, Monconduit M, Belabbes S, Gremy F: A new prognostic classification of chronic lymphocytic leukemia derived from a multivariate survival analysis. Cancer 1981:48:198206.

4 Rai KR, Sawitsky A, Cronkite EP, Chanana AD, Levy RN, Pasternack BS: Clinical staging of chronic lymphocytic leukemia. Blood 1975;46:219-234.

5 Hallek M, Kuhn-Hallek I, Emmerich B: Prognostic factors in chronic lymphocytic leukemia. Leukemia 1997;11(Suppl 2):S4-S13.

6 Zwiebel JA, Cheson BD: Chronic lymphocytic leukemia: Staging and prognostic factors. Semin Oncol 1998;25:42-59.

7 Hallek M, Bergmann M, Emmerich B: Chronische lymphatische Leukämie: Aktualisierte Vorschläge zu Diagnostik und Therapie. Dtsch Ärztebl 2002; 99:A1294-A1301

8 Cheson BD, Bennett JM, Grever M, Kay N, Keating MJ, O'Brien S, Rai KR: National Cancer Institute-sponsored Working Group guidelines for chronic lymphocytic leukemia: Revised guidelines for diagnosis and treatment. Blood 1996;87:4990-4997.

9 Criel A, Michaux L, De Wolf-Peeters C: The concept of typical and atypical chronic lymphocytic leukaemia. Leuk Lymphoma 1999;33:33-45.
10 Moreau EJ, Matutes E, A'Hern RP, Morilla AM, Morilla RM, Owusu-Ankomah KA, Seon BK, Catovsky D: Improvement of the chronic lymphocytic leukemia scoring system with the monoclonal antibody SN8 (CD79b). Am J Clin Pathol 1997;108: 378-382.

11 Harris NL, Jaffe ES, Diebold J, Flandrin G, MullerHermelink HK, Vardiman J, Lister TA, Bloomfield CD: The World Health Organization classification of hematological malignancies report of the Clinical Advisory Committee Meeting, Airlie House, Virginia, November 1997. Mod Pathol 2000;13: 193-207.

12 Döhner H, Stilgenbauer S, Benner A, Leupolt E, Krober A, Bullinger L, Dohner K, Bentz M, Lichter P: Genomic aberrations and survival in chronic lymphocytic leukemia. N Engl J Med 2000;343: 1910-1916.

13 Schultze JL, Donovan JW, Gribben JG: Minimal residual disease detection after myeloablative chemotherapy in chronic lymphatic leukemia. J Mol Med 1999;77:259-265.

14 Wilhelm M, Tony HP, Rueckle-Lanz H, Wilms K: First-line therapy of advanced chronic lymphatic leukemia. Leukemia 1997;11(Suppl 2):S14-S18.

15 Keating MJ, Kantarjian H, O'Brien S, Koller C, Talpaz M, Schachner J, Childs CC, Freireich EJ, Mc Credie KB: Fludarabine: A new agent with marked cytoreductive activity in untreated chronic lymphocytic leukemia. J Clin Oncol 1991;9:44-49.

16 Keating M: Improving the Complete Remission Rate in Chronic Lymphocytic Leukemia. Hematology 1999. American Society of Hematology educational book, 1999, pp 262-269.
17 Keating MJ, O’Brien S, Lerner S, Koller C, Beran M, Robertson LE, Freireich EJ, Estey E, Kantarjian H: Long-term follow-up of patients with chronic lymphocytic leukemia (CLL) receiving fludarabine regimens as initial therapy. Blood 1998;92:11651171

18 Angelopoulou MA, Poziopoulos C, Boussiotis VA, Kontopidou F, Pangalis GA: Fludarabine monophosphate in refractory B-chronic lymphocytic leukemia: Maintenance may be significant to sustain response. Leuk Lymphoma 1996;21:321-324.

19 Montserrat E, Lopez-Lorenzo JL, Manso F, Martin A, Prieto E, Arias-Sampedro J, Fernandez MN, Oyarzabal FJ, Odriozola J, Alcala A, Garcia-Conde J, Guardia R, Bosch F: Fludarabine in resistant or relapsing B-cell chronic lymphocytic leukemia: The Spanish Group experience. Leuk Lymphoma 1996; 21:467-472.

20 Sorensen JM, Vena DA, Fallavollita A, Chun HG, Cheson BD: Treatment of refractory chronic lymphocytic leukemia with fludarabine phosphate via the group $\mathrm{C}$ protocol mechanism of the National Cancer Institute: Five-year follow-up report. J Clin Oncol 1997;15:458-465.

21 Rai KR, Peterson BL, Appelbaum FR, Kolitz J, Elias L, Shepherd L, Hines J, Threatte GA, Larson RA, Cheson BD, Schiffer CA: Fludarabine compared with chlorambucil as primary therapy for chronic lymphocytic leukemia. N Engl J Med 2000;343: 1750-1757.

22 Leporrier M, Chevret S, Cazin B, Boudjerra N, Feugier P, Desablens B, Rapp MJ, Jaubert J, Autrand C, Divine M, Dreyfus B, Maloum K, Travade P, Dighiero G, Binet JL, Chastang C: Randomized comparison of fludarabine, CAP, and ChOP in 938 previously untreated stage $\mathrm{B}$ and $\mathrm{C}$ chronic lymphocytic leukemia patients. Blood 2001;98:2319_ 2325 
23 Cheson BD: Therapy for previously untreated chronic lymphocytic leukemia: A reevaluation. Semin Hematol 1998;35:14-21.

24 Anaissie EJ, Kontoyiannis DP, O’Brien S, Kantarjian H, Robertson L, Lerner S, Keating MJ: Infections in patients with chronic lymphocytic leukemia treated with fludarabine. Ann Intern Med 1998;129: $559-566$.

25 Juliusson G: Complications in the treatment of CLL with purine analogues. Hematol Cell Ther 1997:39(Suppl 1):S41-S4.

26 Cheson BD, Frame JN, Vena D, Quashu N, Sorensen JM: Tumor lysis syndrome: An uncommon complication of fludarabine therapy of chronic lymphocytic leukemia. J Clin Oncol 1998;16:2313-2320.

27 Juliusson G, Christiansen I, Hansen MM, Johnsen S, Kimby E, Elmhorn-Rosenborg A, Liliemark J: Oral cladribine as primary therapy for patients with B-cell chronic lymphocytic leukemia. J Clin Oncol 1996;14:2160-2166.

28 Saven A, Lemon RH, Kosty M, Beutler E, Piro LD: 2-Chlorodeoxyadenosine activity in patients with untreated chronic lymphocytic leukemia. J Clin Oncol 1995;13:570-574.

29 Robak T, Blonski JZ, Kasznicki M, Blasinska-Morawiec M, Krykowski E, Dmoszynska A, MrugalaSpiewak H, Skotnicki AB, Nowak W, Konopka L, Ceglarek B, Maj S, Dwilewicz-Trojaczek J, Hellmann A, Urasinski I, Zdziarska B, Kotlarek-Haus S, Potoczek S, Grieb P: Cladribine with prednisone versus chlorambucil with prednisone as first- line therapy in chronic lymphocytic leukemia: Report of a prospective, randomized, multicenter trial. Blood 2000;96:2723-2729.

30 Grillo-Lopez AJ, White CA, Varns C, Shen D, We A, McClure A, Dallaire BK: Overview of the clinical development of rituximab: First monoclonal antibody approved for the treatment of lymphoma. Semin Oncol 1999;26:66-73.

31 Dyer MJ: The role of CAMPATH-1 antibodies in the treatment of lymphoid malignancies. Semin Oncol 1999;26:52-57.

32 Nguyen DT, Amess JA, Doughty H, Hendry L, Diamond LW: IDEC-C2B8 anti-CD20 (rituximab) immunotherapy in patients with low-grade nonHodgkin's lymphoma and lymphoproliferative disorders: Evaluation of response on 48 patients. Eur J Haematol 1999;62:76-82.

33 Huhn D, von Schilling C, Wilhelm M, Ho AD, Hallek M, Kuse R, Knauf W, Riedel U, Hinke A, Srock S, Serke S, Peschel C, Emmerich B and German CLL Study Group: Rituximab therapy of patients with B-cell chronic lymphocytic leukemia. Blood 2001;98:1326-1331.

34 O'Brien S, Kantarijan H, Thomas D, Giles F, Freireich E, Cortes J, Lerner S, Keating M: Rituximab dose-escalation trial in chronic lymphocytic leukaemia. J Clin Oncol 2001;19:2165-2170.

35 Byrd J, Murphy T, Howard R, Lucas M, Goodrich A, Pearson M, Waselenko J, Ling G, Grever M, Grillo-Lopez A, Rosenberg J, Kunkel L, Flinn I: Rituximab using a thrice weekly dosing schedule in B-cell chronic lymphocytic leukemia and small lymphocytic lymphoma demonstrates clinical activity and acceptable toxicity. J Clin Oncol 2001;19:21532164.

36 Kunzmann V, Ruediger T, Hallek M, Mueller-Hermelink HK, Wilhelm M: Tumor cell agglutination and not solely cytokine release as mechanism of adverse reactions during anti-CD20 monoclonal antibody (IDEC-C2B8, rituximab) treatment. Blood 2001; 98:1991-1992.

37 Winkler U, Jensen M, Manzke O, Schulz H, Diehl $\mathrm{V}$, Engert A: Cytokine-release syndrome in patients with B-cell chronic lymphocytic leukemia and high lymphocyte counts after treatment with an anti-CD20 monoclonal antibody (rituximab, IDECC2B8). Blood 1999;94:2217-2224.
38 Tang SC, Hewitt K, Reis MD, Berinstein NL: Immunosuppressive toxicity of CAMPATH1H monoclonal antibody in the treatment of patients with recurrent low grade lymphoma. Leuk Lymphoma 1996;24:93-101.

39 Osterborg A, Dyer MJ, Bunjes D, Pangalis GA, Bastion Y, Catovsky D, Mellstedt H: Phase II multicenter study of human CD52 antibody in previously treated chronic lymphocytic leukemia. European Study Group of CAMPATH-1H Treatment in Chronic Lymphocytic Leukemia. J Clin Oncol 1997;15:1567-1574.

40 Osterborg A, Fassas AS, Anagnostopoulos A, Dyer MJ, Catovsky D, Mellstedt H: Humanized CD52 monoclonal antibody Campath- $1 \mathrm{H}$ as first-line treatment in chronic lymphocytic leukaemia. Br J Haematol 1996;93:151-153.

41 Dyer MJ, Kelsey SM, Mackay HJ, Emmett E, Thornton P, Hale G, Waldmann H, Newland AC, Catovsky D: In vivo 'purging' of residual disease in CLL with Campath-1H. Br J Haematol 1997;97: 669-672.

42 Bellosillo B, Villamor N, Colomer D, Pons G, Montserrat E, Gil J: In vitro evaluation of fludarabine in combination with cyclophosphamide and/or mitoxantrone in B-cell chronic lymphocytic leukemia. Blood 1999;94:2836-2843.

43 Zaja F, Rogato A, Russo D, Marin L, Silvestri F, Baccarani M: Combined therapy with fludarabine and cyclophosphamide in relapsed/resistant patients with B-cell chronic lymphocytic leukaemia and non-Hodgkin's lymphomas. Eur J Haematol 1997; 59:327-328.

44 Hallek M, Schmitt B, Wilhelm M, Emmerich B, Kröber A, Fostitsch HP, Sezer O, Herold M, Knauf W, Busch B, Wendtner CM, Kuse R, Freund M, Franke A, Schriever F, Nerl C, Döhner H, Thiel E, Hiddemann W, Brittinger C, Emmerich B and Germany CLL Study Group: Fludarabine plus cyclophosphamide for the treatment of chronic lymphocytic leukemia: Results of a phase II study (CLL2 protocol) of the German CLL Study Group (GCLLSG). Br J Haematol 2001;114:342-348.

45 O'Brien S, Kantarjian H, Cortes J, Beran M, Koller C, Giles F LE, Lerner S, Keating M: Results of the fludarabine and cyclophosphamide combination regimen in chronic lymphocytic leukemia. J Clin Oncol 2001;19:1414-1420.

46 Frewin R, Turner D, Tighe M, Davies S, Rule S, Johnson S: Combination therapy with fludarabine and cyclophosphamide as salvage treatment in lymphoproliferative disorders. Br J Haematol 1999;104: 612-613.

47 Flinn IW, Byrd JC, Morrison C, Jamison J, Diehl LF, Murphy T, Pianatodosi S, Seifter E, Ambinder RF, Vogelsang G, Grever MR: Fludarabine and cyclophosphamide with filgastrim support in patients with previously untreated indolent lymphoid malignancies. Blood 2000;96:71-75.

48 Rummel MJ, Kafer G, Pfreundschuh M, Jager E, Reinhardt U, Mitrou PS, Hoelzer D, Bergmann L: Fludarabine and epirubicin in the treatment of chronic lymphocytic leukaemia: A German multicenter phase II study. Ann Oncol 1999;10:183-188.

49 Bosch F, Ferrer A, Lopez-Guillermo A, Gine A, Cobo F, Perales M, Esteve J, Villamor N, Colomer D, Bellosillo B, Ribera JM, Altes A, Besalduch J, Montserrat E: Fludarabine with cyclophosphamide and mitoxantrone (FCM) in resistant or relapsed chronic lymphocytic leukaemia (CLL): Final results of a phase II study. Blood 2001;98(Suppl 1):abstr 2655 .
50 Wierda W, O'Brien S, Albitar M, Lerner S, Plunkett W, Giles F, Andreef M, Cortes J, Faderl S, Thomas D, Koller C, Kantarijan H, Keating M: Combined fludarabine, cyclophosphamide and rituximab achieves a high complete remission rate as initial treatment for chronic lymphocytic leukemia. Blood 2001;98(Suppl 1):abstr 3210.

51 Byrd J, Peterson B, Park K, Morrison V, Vardiman J, Jacobson R, Rai K, Larson R: Concurrent rituximab and fludarabine has a higher complete response rate than sequential treatment in untreated chronic lymphyocytic leukemia (CLL) patients: Results from CALGB 9712. Blood 2001;98(Suppl 1):abstr 3212.

52 Manero GG, O'Brien S, Cortes J, Faderl S, Giles F, Albitar M, Lerner S, Kantarijan H, Keating M: Update of results of the combination of fludarabine, cyclophosphamide and rituximab for previously treated patients with chronic lymphocytic leukemia (CLL). Blood 2001;98(Suppl 1):abstr 2650.

53 Schulz H, Klein SH, Rehwald U, Reiser M, Hinke A, Knauf WU, Aulitzky WE, Hensel M, Herold M Huhn D, Hallek M, Diehl V, Engert A: Phase II study of a combined immunochemotherapy using rituximab and fludarabine in patients with chronic lymphocytic leukemia. Blood 2002;100:3115-3120.

54 Kennedy B, Rawstron A, Carter C, Ryan M, Speed K, Lucas G, Hillmen P: Campath-1H and fludarabine in combination are highly active in refractory chronic lymphocytic leukemia. Blood 2002;99: 2245-2247.

55 Wendtner CM, Kurzeder C, Kofler D, Edbauer D, Buhmann R, Hallek M: Innovative Therapieansätze; in Hallek M, Emmerich B (Hrsg): Chronische lymphatische Leukämie. Bremen, Uni-Med, 2001, pp 116-122.

56 Byrd JC, Grever MR: Finding new therapies for patients with chronic lymphocytic leukemia; in Cheson B (ed): Chronic Lymphoid Leukemias. New York, NY, Marcel Dekker, Inc. 2001, pp 417-434.

57 Meloni G, Proia A, Mauro F, Amaranto P, Capria S, Cimino G, Cordone I, de Fabritiis P, Rapanotti C, Reato G, Vignetti M, Foa R, Mandelli F: Unmanipulated peripheral blood stem cell autograft in chronic lymphocytic leukemia: Clinical findings and biological monitoring. Haematologica 2000;85:952960.

58 Dreger P, Michallet M, Schmitz N: Stem-cell transplantation for chronic lymphocytic leukemia: The 1999 perspective. Ann Oncol 2000;11:49-53.

59 Waselenko JK, Flynn JM, Byrd JC: Stem-cell transplantation in chronic lymphocytic leukemia: The time for designing randomized studies has arrived. Semin Oncol 1999;26:48-61.

60 Khouri IF, Keating M, Korbling M, Przepiorka D, Anderlini P, O'Brien S, Giralt S, Ippoliti C, von Wolff B, Gajewski J, Donato M, Claxton D, Ueno N, Andersson B, Gee A, Champlin R: Transplantlite: Induction of graft-versus-malignancy using fludarabine-based nonablative chemotherapy and allogeneic blood progenitor-cell transplantation as treatment for lymphoid malignancies. J Clin Oncol 1998;16:2817-2824.

61 Toze CL, Shepherd JD, Connors JM, Voss NJ, Gascoyne RD, Hogge DE, Klingemann HG, Nantel SH, Nevill TJ, Phillips GL, Reece DE, Sutherland HJ, Barnett MJ: Allogeneic bone marrow transplantation for low-grade lymphoma and chronic lymphocytic leukemia. Bone Marrow Transplant 2000;25:605-612.

62 Gribben JG: Stem-cell transplantation for indolent lymphoma. Semin Hematol 1999;36:18-25.

63 Diehl LF, Ketchum LH: Autoimmune disease and chronic lymphocytic leukemia: Autoimmune hemolytic anemia, pure red cell aplasia, and autoimmune thrombocytopenia. Semin Oncol 1998;25:80-97. 